\title{
Os fanzines e o posicionamento ideolóxico. Poden transmitir posicións ideolóxicas os fanzines?
}

\author{
Ramón Mariño Fernández \\ UNIVERSIDADE DE SANTIAGO DE COMPOSTELA, GALICIA, ESPAÑA \\ ramonfm72@gmail.com
}

\begin{abstract}
Resumo: As publicacións amateurs denominadas fanzines colleron forza a partir dos anos 70 do século XX para expresaren ideas e posicións de grupos considerados á marxe do común, do habitual e das grandes cadeas de consumo mediático. O seguinte artigo busca dar resposta á pregunta de se as persoas que crean, editan e distribúen fanzines o fan motivadas por unha postura ou posición ideolóxica. Para este artigo pártese da tese doutoral O fanzine e a ruptura do monopolio da mensaxe. Uso dos fanzines como medios informativos e de expresión en Galicia. 1990-2005, de Ramón Fernández Mariño (2015). A partir deste documento recóllense tanto a definición de fanzine como de ideoloxía, para buscar os elos que permitan ter unha resposta acaída academicamente á pregunta que se presenta neste artigo.
\end{abstract}

Palabras chave: fanzine, ideoloxía, creación, medios, comunicación, cultura

Abstract: The amateur publications called fanzines came into force from the 1970 s to express ideas and positions of groups considered out of the ordinary, the mainstream and the large media consumption chains. The following article seeks to answer the question of whether people who create, edit, and distribute fanzines do so because of their ideological stance or position. This article is based on the doctoral thesis The fanzine and the breaking of the message monopoly. Use of fanzines as information and expression media in Galicia. 1990-2005, by Ramón Fernández Mariño (2015). From that document, both the definition of fanzine and ideology are collected, in order to look for the links that allow an academic answer to the question presented in this article.

Keywords: fanzine, ideology, creation, media, communication, culture.

\section{Que é un fanzine?}

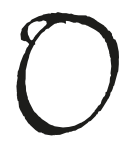

fanzine é unha publicación amateur realizada por persoas con intereses en común e que desexan transmitir as súas opinións e creacións sobre un ou varios temas. Estas publicacións fanse sen ánimo de lucro, tendo ás veces prezos simbólicos fundamentais para cubrir os gastos da edición. A maioría deles non teñen unha liña editorial clara -ben por espontaneidade ou por vontade propia dos autores para abrir o espectro de creacións e posturas que enchan as páxinas- e a distribución é feita normalmente polas propias persoas involucradas na creación 
do folleto. Outro trazo importante é o efémero da vida destas publicacións. Algúns fanzines poden sobrevivir un período longo, mais o normal é que non pasen de dous ou tres anos de existencia. Isto foi comprobado coas entrevistas realizadas para a nosa tese (2015: 327-360), onde grupos de persoas apuntaron primeiro unha mínima continuidade (seis meses mínimo entre o primeiro e segundo número), ampliación desa periodicidade (un ano entre o último publicado e o seguinte) e/ou desaparición, debida sobre todo aos compromisos persoais e laborais que impedían continuar co proxecto. Como exemplos prácticos: o fanzine Lixo Urbano, nacido a comezos dos 90 en Santiago de Compostela, tivo un só número; pola contra, o fanzine As cousas claras, tamén de comezos dos 90 e distribuído na comarca do Deza, tivo unha vida de sete números e mantívose activo durante case unha década, con espazos temporais amplos entre as súas saídas.

Imaxe 1

Fanzine As cousas claras

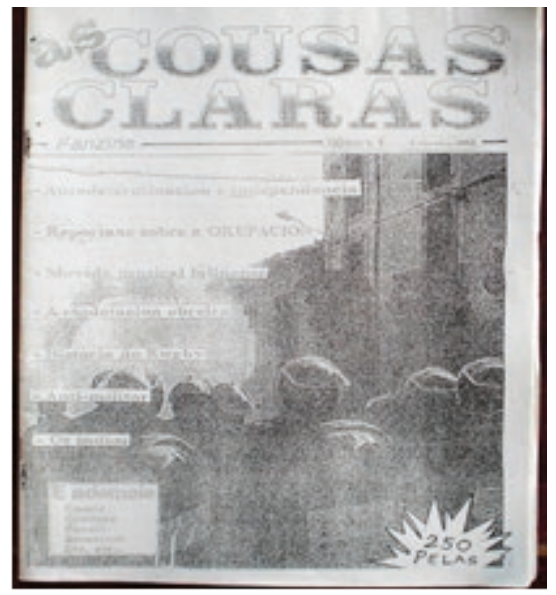

Imaxe 2

Fanzine Lixo urbano

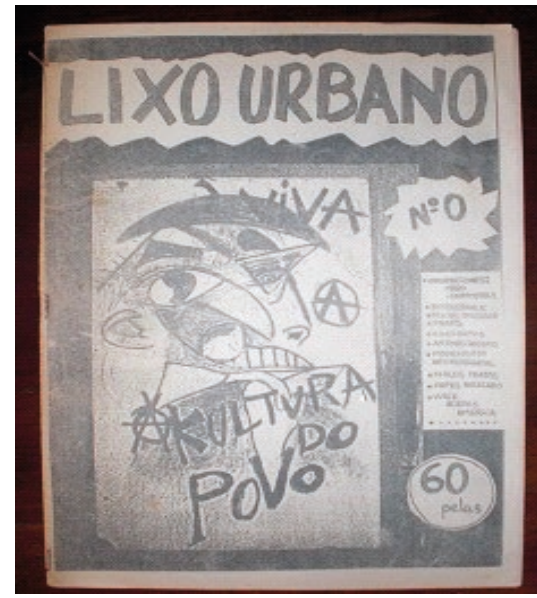

A iniciativa para crear un fanzine pode ser individual ou colectiva e as temáticas varían enormemente entre eles. Unha única persoa pode crear varias cabeceiras, cada unha abordando unha temática diferente, porén os fanzines nacidos a partir da segunda metade do século XX foron traballos máis colectivos que reflectían diferentes sensibilidades sobre diferentes temas (Sabin e Teal, 2000: 12,13). Aínda así, a falta de liña editorial na maioría dos casos permitiu a pervivencia de certo individualismo dentro do grupo creativo. 
Historicamente, o termo "fanzine" naceu en 1940 da man de Louis Russell "Russ" Chauvenet, quen creara o que sería coñecido como o primeiro exemplar do xénero: Detours (http://fancyclopedia.org/Detours). O mesmo Chauvenet creou tamén o termo "fandom" para referirse ao círculo de fans da ciencia-ficción (Ci-Fi) (Fiske, 1994: 146, 147), (https://es.wikipedia.org/wiki/Fandom). Co tempo, a denominación "fandom" acabou referíndose, por extensión, aos círculos de persoas que seguen unha publicación como as que describimos, sen importar a temática que aborda (Moskowitz e Sanders, 1994: 17-36). Con todo, débese dicir que antes do Detours xa existía o The Comet, considerado precursor do fanzine de ciencia-ficción, aínda que non recibía esta denominación porque non fora inventada até dez anos despois por Chauvenet. The Comet nacera en Chicago a comezos dos anos 30 do século XX e fora creado pola Science Correspondence Club (Moskowitz e Sanders, 1994: 17-36).

Imaxe 3

Fanzine Detours (1940)

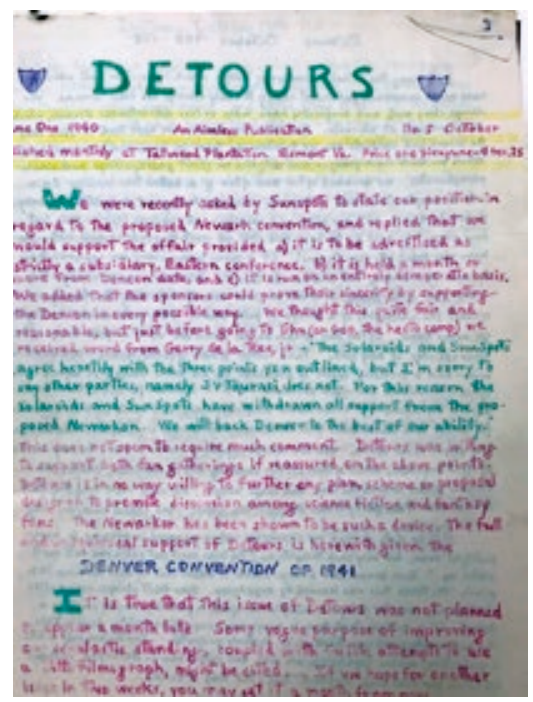

Imaxe 4

Russ Chauvenet (1920-2003)

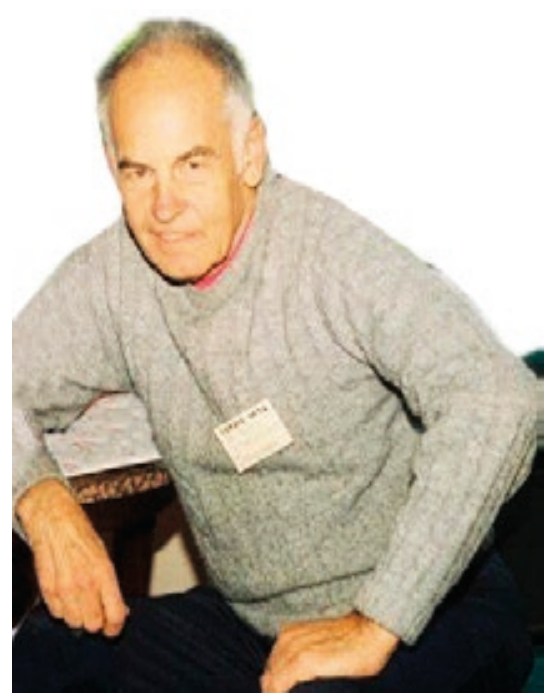

As temáticas que abordan son diversas. Os primeiros fanzines contemporáneos eran publicacións sobre todo de ciencia-ficción (Ci-Fi). Logo naceron outros especializados en materias como literatura ou banda-deseñada. A partir dos anos 70 do século $\mathrm{XX}$ apareceron publicacións semellantes que se afastaban deses primeiros temas para trataren cuestións políticas, ecoloxistas, pacifistas e todo tipo de expresión cultural e 
política fóra dos circuítos oficiais e comerciais (Abril, 2010: 25). Esta nova eclosión de folletos fixo que, sobre todo no mundo algosaxón, se distinguise entre "fanzine", publicación centrada en ciencia-ficción e outras expresións culturais, e "zine" para as publicacións que mesturaban tanto cuestións políticas como culturais desde a segunda metade dos 70 (Bartel, 2004: 6 e Atton, 2002: 57).

Imaxe 5

Fanzine The Comet. Ciencia-ficción (1930)

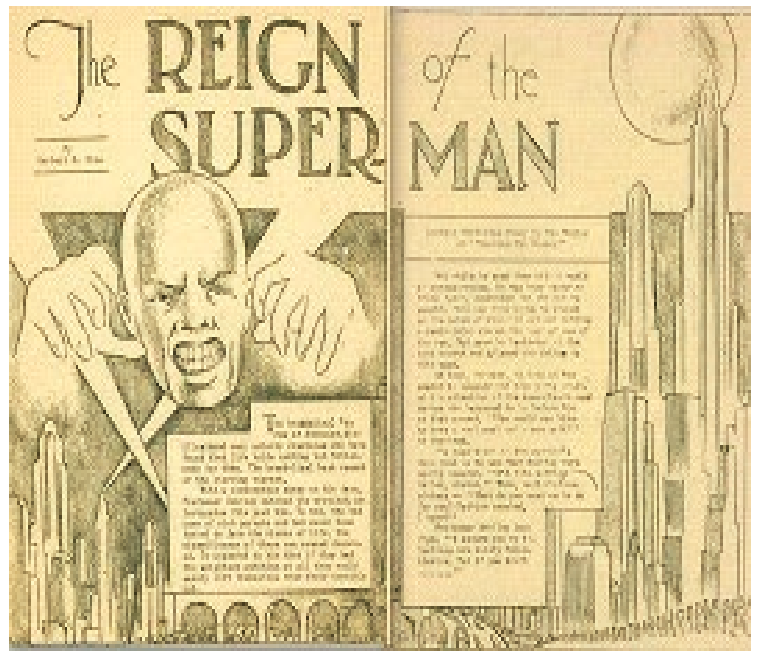

Imaxe 6

Zine Liñas de Paz. Política, antimilitarismo (1991)

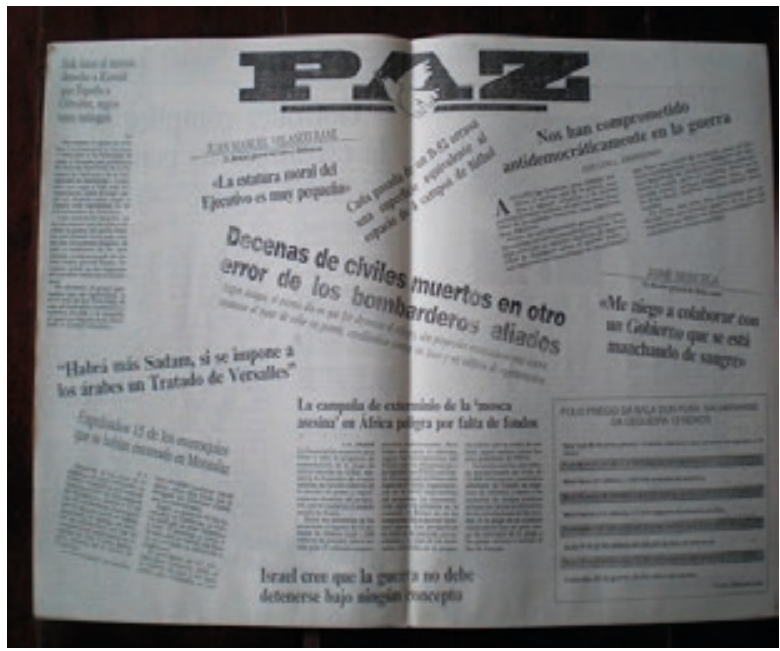


Neste artigo usamos o termo "fanzine" para ambas as dúas modalidades. O motivo desta elección é que o uso de "fanzine" é o máis empregado por autores e autoras en Galicia e no resto de España. Pódese comprobar na nosa tese $O$ fanzine e a ruptura do monopolio da mensaxe. Uso dos fanzines como medios informativos e de expresión en Galicia. 1990-2005 (Fernández Mariño, 2015: 249-360). Durante as entrevistas realizadas para este traballo de investigación, as persoas relacionadas coa creación das publicacións deste xénero feitas en Galicia mencionaban con maior frecuencia o termo "fanzine". En realidade, o termo "zine" só se encontrou nalgunhas publicacións e nas entrevistas tivo un emprego testemuñal. Reforzando isto, as persoas consultadas non facían a distinción técnica "fanzine/zine", aínda que a maioría das publicacións en que interviron tiñan máis proximidade co "zine" que co "fanzine" en sentido estricto.

\section{Transformaciōn, nanomedios e "fandom"}

O "fanzine" transformouse en vía de comunicación para grupos que estaban fóra das tendencias culturais, políticas e de calquera tipo de expresión máis "comerciais" ou "politicamente correctas". Usando linguaxes escritas e gráficas diferentes (Abril, 2010: 42-47), estes fanzines convertéronse en altofalantes de diferentes movementos, sobre todo urbanos, en Occidente (Atton, 1996: 23). A razón desta transformación foi a falta de "sitio" en medios comerciais ou convencionais para estes novos movementos (Hebdige, 2013: 91). Buscábase a ruptura cos modelos establecidos, dos culturais aos comerciais, creando unhas expresións culturais "na fronteira", "arraianos" ou "de ruptura" ("fringe culture") (Atton, 1996: 58).

Aqueles grupos "arraianos" ou posicionados "na fronteira”, inclúen os grupos "fandom" e os vinculados a movementos contrarios ás políticas sociais, económicas e laborais do contexto temporal, social e político en que se desenvolveron. Isto materialízase coa aparición de grupos que reflicten os seus pareceres en publicacións como son os mesmos fanzines. O obxectivo é chegar a un público cada vez maior (Perkins, 1992) e esa meta, debido ás limitacións da distribución man en man, é imposible. Ademais diso, os e as creadoras de fanzines manteñen un ritmo de creación moi desigual, con períodos irregulares de aparición entre un número e o que lle segue. Isto pode ser un motivo que desalente á pervivencia da publicación que ao mellor non pasa dos cinco números de media, con escasas excepcións que sobrepasen os dez números.

O limitado número de receptores a que poden chegar estas publicacións insíreas no denominado grupo de "nanomedios", o que Downing describe como medios de pequena escala. Primeiro denomínaos "medios alternativos radicais" e despois "medios de movementos sociais", porque entende que están ligados a movementos sociais e políticos e porque desde eles é posible elaborar unha esfera pública alternativa aos poderes económicos, relixiosos ou gubernamentais (Downing, 2010). 
Imaxe 7

Fanzine Noxxxo, (Ourense 1992), exemplo de "fringe culture" en Galica

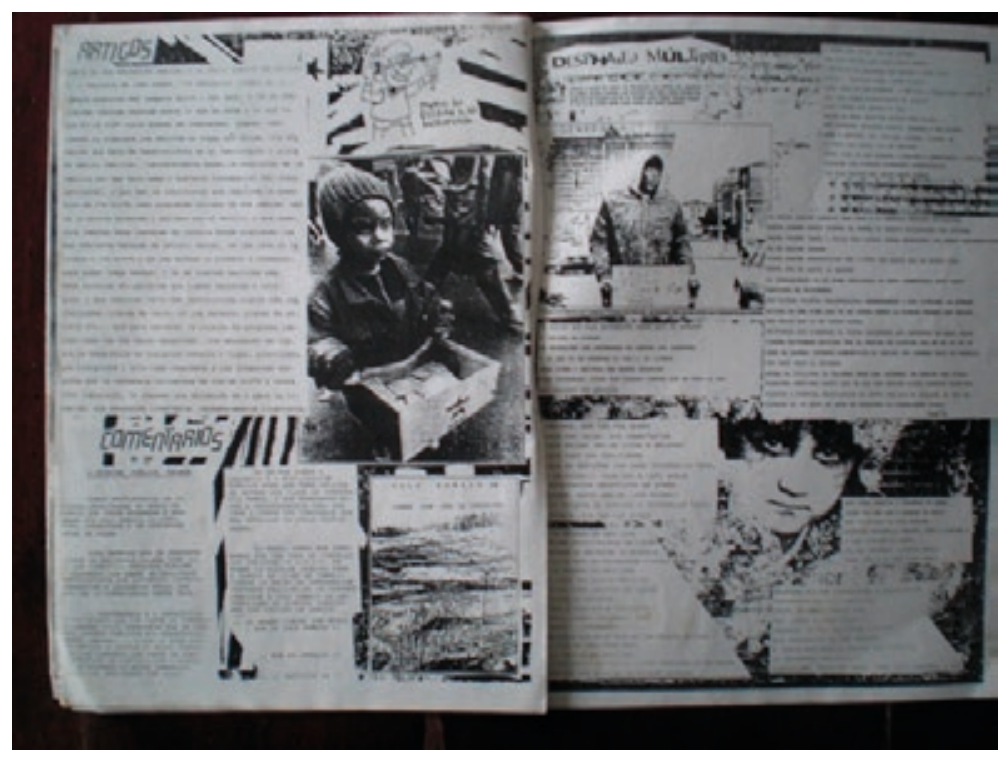

Imaxe 8

Fanzine de temática cinéfila Dalhe!!! (2007)

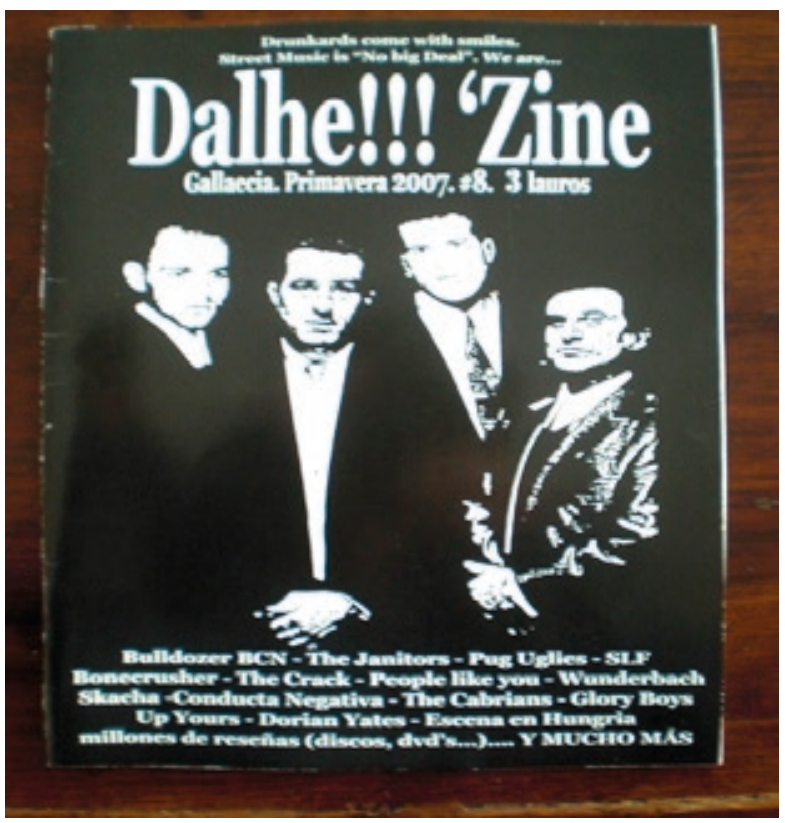




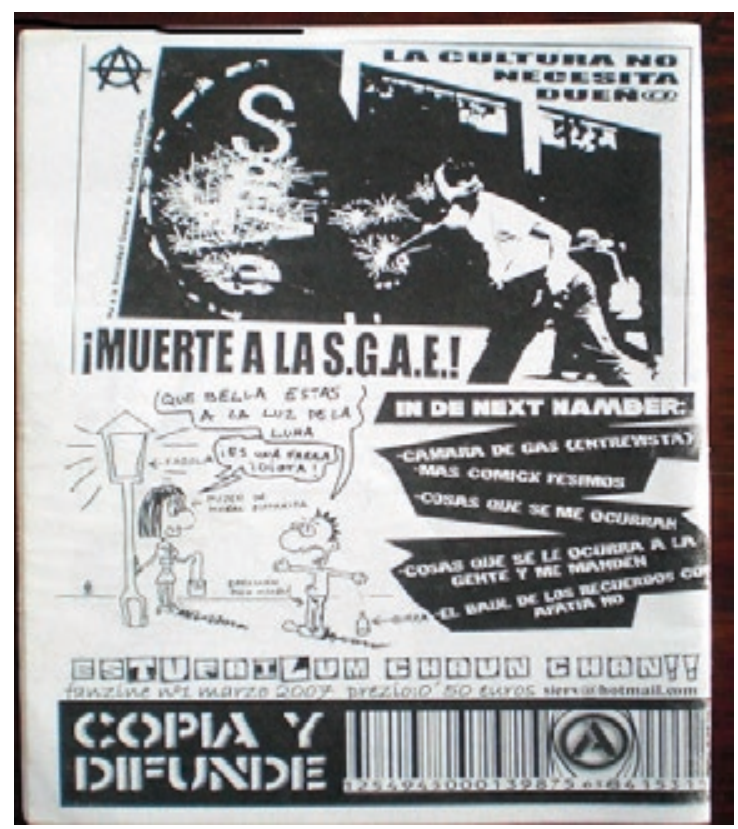

Por outra parte, Downing non ve o fanzine, dentro dun sentido de artefacto elaborado por fans, como outro "medio de movementos sociais". Aínda que recoñece a súa natureza de medio de pequena escala, mesmo cando rastrexa as orixes destes nanomedios non ve esa ligazón con movementos sociais simplemente porque non todos os fanzines a podan ter (Downing, 2010: 20; Fernández Mariño, 2015: 321).

O fandom, "dominio dos fans", é unha comunidade social alternativa en que a produción cultural é usada para construír e para manter lazos solidarios dentro desa comunidade de fanáticos (Jenkins, 1992). Lembremos que o fanzine tamén foi fundamental para unha subcultura moi particular, o fandom de cine de culto, un tipo de cinema á marxe, onde os autores e autoras puideron crear os seus propios valores, virtudes e o seu cánone que moitas veces podía ir máis alá das normas sociais e sexuais máis convencionais. (Fernández Mariño, 2015: 321). 


\section{O fanzine como transmisor de posicións ideolóxicas}

Calquera posicionamento político ou social precisa dunha vía de transmisión para que a cidadanía poda ter coñecemento del. Os mesmos grupos que manifestan desafección ou posturas contrarias ao contexto socio-político que os envolve senten a necesidade de crear os seus propios medios para difundir esa desafección. Detrás desa necesidade hai unha postura ideolóxica que busca consolidarse como influencia dentro da sociedade.

Os fanzines poden transmitir ideoloxías? Sendo un medio de comunicación (nanomedio) que transmite a postura dunha comunidade (fandom ou colectivos máis comprometidos) que posúe uns valores determinados (ecoloxismo, anarquismo, antisistema, creación fóra do circuíto comercial, etc.), podería dicirse que o fanzine si transmite ideoloxía. A base para fundamentar esta resposta podemos extraela da definición que aporta Terry Eagleton: "O proceso de producción de significados, signos e valores na vida cotiá” (Eagleton, 1997: 19, 20). Este proceso é o elemento que mellor define o fanzine desde unha perspectiva ideolóxica. As súas páxinas recollen os tres puntos sinalados, que axudan a definir un grupo determinado dentro dun contexto social máis amplo.

Páxinas interiores dun fanzine do movemento "Riot Grrrl". Este movemento reclamaba, entre outros puntos, a desaparición do sexismo dentro do mundo da música en EE UU.

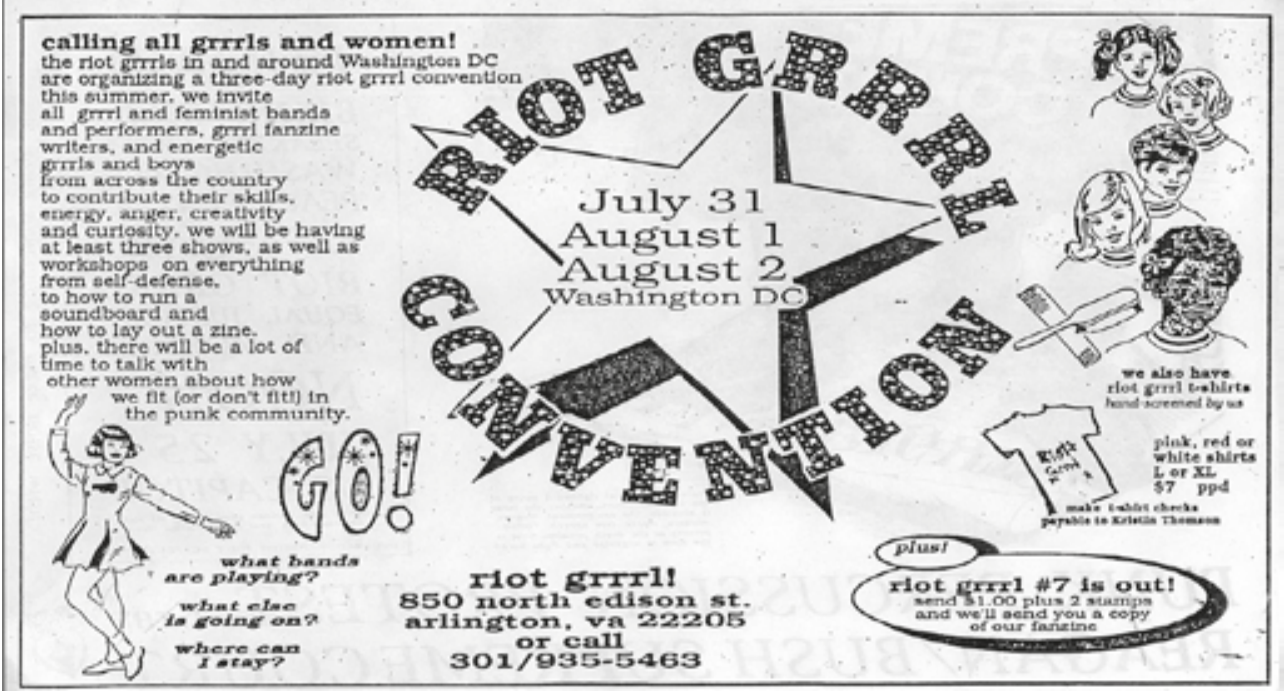


A causa desta produción de significados, signos e valores corresponde moitas veces a unha postura colectiva (normalmente minoritaria dentro dun contexto social máis amplo) que busca "romper maneiras dominantes" socialmente, para deixar pasar novos tipos de expresión en diferentes ámbitos. Estas citadas "maneiras dominantes" son definidas por John B. Thompson como "poder cultural ou poder simbólico" cunha forte intervención sobre os acontecementos que reflicte o proceso comunicativo entre individuos (Thompson, 1998: 23, 24). Este proceso comunicativo envía unha idea creada por "uns" para influír en "outros". Mais os "outros" buscan separarse da mensaxe creada desde os "uns" mediante a aparición de novas vías de expresión e comunicación. Isto traduciríase en "fendas" comunicativas, sociais e políticas dentro da maioría social. Esas fendas materializaríanse en novos grupos políticos e sociais con novas posturas sobre temas como emprego, vivenda, renda social, antirracismo, ecoloxía, inmigración, relixión e outros (McLuhan, 2009: 31).

\section{Imaxe 12 e Imaxe 13}

Fóbico (esq.) era un fanzine portugués de liña "animalista". Pedras contra balas, en Lalín nos comezos dos 2000, expuña ideas contrarias tanto á clase política como algúns representantes da mesma. Ambos os dous manifestaban posturas sociais e políticas en contra do sistema establecido.
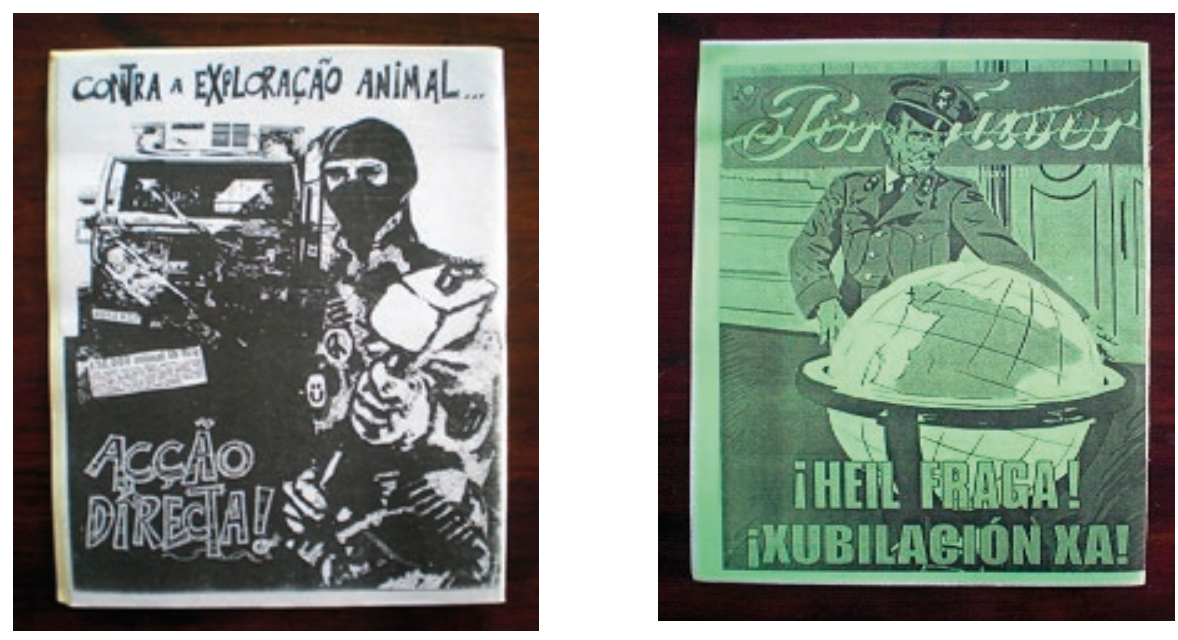

As "fendas" son lugares de creación tanto de significados, signos e valores que ás veces funcionan como elementos motivadores para a acción (Eagleton, 1997: 20). Isto materialízase en confrontacións, directas ou indirectas, contra o "estado das cousas" imperante nunha ou varias sociedades contemporáneas polo seu estilo de vida, 
modelo político, etc. Un exemplo disto serían os fanzines e os creadores dos mesmos nos Estados Unidos durante a década de 1990. O obxectivo era a crítica ao estilo de vida capitalista deste país (Abril, 2010: 47).

\section{Actividade política}

Hai ensaístas que consideran tanto o fanzine e as persoas involucradas na súa creación como "politicamente activos" mais non cun sentido tradicional de actividade política. A investigadora Julie Bartel entende que si hai posicionamento político, mais fóra tanto dos partidos parlamentarios como extra-parlamentarios. A mesma Bartel sinala que as persoas detrás dun fanzine fuxen do apelativo "político" para autodenominarse "activistas" dentro de todos os "ismos" (sic): ecoloxismo, feminismo, antimilitarismo, altermundismo, etc. (Bartel, 2004: 19).

Con todo o respecto que nos merecen esas valoracións, non debemos esquecer que o fanzine naceu como unha plataforma de expresión individual, aínda que haxa aportacións doutras persoas. Todas as expresións que aparecen nestas publicacións veñen desde unha visión moi subxectiva da realidade en todos os seus aspectos (Abril, 2010:48). O que realmente fai o fanzine é dar saída a esas posicións individuais mediante unha mínima cohesión.

En resumo, podemos concluír que si hai ideoloxía detrás do fanzine e esa ideoloxía é unha conxunción de diferentes puntos de vista persoais que empurarron a crear a cabeceira. Esa publicación é unha resposta a un "estado das cousas" mediático, político e social determinado que non satisfai nin a quen crea ese fanzine nin a quen o le. E esa ideoloxía ten un nome?

\section{Do It Yourself (DIY) "Faino ti mesmo"}

Partindo de novo desde Eagleton e a definición de ideoloxía como "o proceso de produción de significados, signos e valores na vida cotiá", entendemos que este proceso de produción implica o uso de ferramentas axeitadas, ou como di Thompson "technical medium" (Thompson, 1996: 36-38). Este medio técnico é o que permite a creación de formas simbólicas durante un espazo de tempo, ademais da almacenaxe de información e contido simbólico. Por outra parte, permite a reprodución ou a copia dunha mensaxe case de maneira infinita. O medio técnico facilitou que os fanzines chegasen a un público xeral, pero en número limitado, ou a un público específico.

O medio técnico -ou medios técnicos porque sempre foron máis de un- comezaron pola simple edición nun folio onde se podían combinar texto e debuxo, usando as ferramentas de que se dispoñía: bolígrafos, lapis, papel, tesoiras, revistas para facer collage, etc. Para a reprodución en principio existían os limógrafos ou "vietnamitas". 
Mais, a partir dos anos 80 en España, a comercialización das fotocopiadoras abriu a posibilidade a unha maior expansión e difusión dos fanzines. Moitas veces esa reprodución era praticamente gratuíta ou facíase a un prezo moi baixo. Ese foi o grande avance para a difusión de fanzines, tanto en Galicia como no resto de España (Fernández Mariño, 2015: 54).

Debemos ter en conta que os medios técnicos poden separar unha forma simbólica do seu contexto e logo inserila noutro contexto que podería estar nun tempo e lugar diferentes, o que Thompson define como "separación espazo-temporal". Desta maneira, podemos modificar tecnicamente o discurso co que se exerce o poder. Isto é posible co uso de habilidades, competencias e formas de coñecemento encamiñadas á manipulación dos medios técnicos. Débense, entón, coñecer ben as regras e procedementos relevantes para levalos ao terreo práctico cando usemos un soporte técnico de comunicación. Porén, é necesario diferenciarmos entre aquelas competencias que nos permiten codificar a mensaxe ou discurso e as competencias que nos permiten descodificar a mensaxe. Resumindo as ideas de Thompson, podemos dicir que debe haber cando menos un discurso para ser reproducido mediante un procedemento técnico para amplialo, mesmo co risco -intencionado ou non- de alteralo mediante a descontextualización ou recontextualización. Todo isto non sería posible de non ser por medios técnicos e recursos culturais que permiten codificar e decodificar o discurso e/ou a mensaxe. Desta maneira, cando menos debe haber un discurso para ser reproducido mediante un procedemento técnico que o amplíe, mesmo co risco de alteralo mediante a descontextualización ou recontextualización. Todo isto non sería posible de non ser por medios técnicos e recursos culturais que permiten tanto codificar como descodificar o discurso e/ou a mensaxe. Finalmente, tendo en conta o xa mencionado poder simbólico (Thompson, 1996: 38-43) e a referencia de Eagleton á ideoloxía como "o proceso de produción de significados, signos e valores na vida cotiá", teriamos unha mistura de argumentos que describirían o do DIY (faino ti mesmo).

O DIY pode ser visto tanto como unha postura ideolóxica individual como colectiva, como unha resposta á necesidade ou precariedade de quen carece do acceso aos medios técnicos apuntados por Thompson. José Ángel Abril define o DIY como: “(...) una producción contracultural de origen "underground" que implica una actitud de confrontación con un componente de autogestión, según la cual cualquiera puede producir y promocionar su producto saltándose las leyes básicas de mercado de la sociedad capitalista" (Abril, 2010: 51).

Juan Ignacio Gallego Pérez en "Do It Yourself, cultura y tecnología”, artigo publicado en Icono, afirma que o DIY é unha rebelión fronte a un poder establecido, un 
desexo de romper xerarquías e crear algo novo fronte ao que considerado "establecido", "medios masificados" ou "esteticamente de escaso interese".

Nun maior nivel de concreción, Chris Atton, apoiándose en máis autores, chega a distinguir entre dúas versións do DIY: cultural e político.

No que toca ao DIY político (DIY politics), Atton fai cita de Senseless Acts of Beauty: Cultures of Resistance since the Sixties, (Atton, 2002: 82), o traballo de George McKay para explicar este fenómeno. Debido ás medidas de seguridade que tanto os estados, quer coa policía, quer coas forzas armadas ou ben con empresas privadas contratadas para manter a orde, os activistas dos diversos movementos usan novas tácticas para evitar as medidas coercitivas por parte das "forzas da orde". Aquí o DIY consistiría no uso de túneles para superar muros físicos ou sociais, creación de festas dándolles a característica de "protesta" (diversión para amolar). Todo isto facíase co uso de novos métodos de comunicación para organizarse (hoxe en día a rede de redes, Internet), mais non debemos esquecer que McKay describíu estas tácticas durante o período chamado New Protest dos anos noventa (a protesta de Seattle, 1999 sería o momento culminante deste movemento).

O segundo DIY é o cultural. Refírese á creación tanto de novas maneiras de expresión artísitica e comunicativa como de novas vías para a súa transmisión. É unha acción realizada por "activistas" (Atton, 1996:86). O mesmo Atton descobre que no Reino Unido nos anos setenta do século XX houbo unha xerarquización e profesionalización do que os investigadores sociais denominaron "social movements organizations" (SMO). Quere isto dicir que daquela quen fose activista de movementos como o ecoloxista, o pacifista ou polos dereitos sociais, acabou deixando o activismo "voluntarista" por un activismo máis "profesionalizado" e imitador das maneiras doutras organizacións sindicais, políticas e empresariais tradicionais.

Non obstante, a non-profesionalización, quer espontánea, quer buscada e por tanto consensuada dentro dun movemento, é un elemento moito máis exitoso que a total xerarquización e profesionalización dos movementos sociais (Eyerman e Jamison, 1991: 106, citado en Atton, 1996: 120). Para o Atton un exemplo disto sería o anonimato e/ou uso de pseudónimos contra o personalismo dentro das asociacións e as redes de asociacionismo de acción-directa nacidas no Reino Unido durante a década dos noventa do século XX. Isto ao final traducíuse nunha "cultura de faino ti mesmo" (poderiamos traducir por “organízate ti mesmo” neste caso). Máis aínda, ao seren grupos de persoas organizándose en redes máis amplas e entre eles, denominarían á "cultural DIY” como "cultura DiO" (DO it OURSELVES, “cultura de facelo nós mesmos") (Atton, 1996: 120).

A coordinación entre os diferentes grupos que conformarían o DIY cultural sería algo espontáneo, unha relación que nacería dun achegamento entre eles con 
final tan espontáneo como cando se xuntaron. A “descentralización” sería unha das claves para a sobrevivencia dos medios e da cultura DIY (Atton, 1996: 127). Por outra parte, esa descentralización, falta de xerarquías e/ou modelos de dirección "clásicos", fai que máis dunha vez os fanzines sexan considerados como vehículos de expresións políticas ou ideolóxicas moito máis radicais que o ecoloxismo ou pacifismo. Isto vén acontecendo desde o último cuarto do século XX para adiante, cando se identificou "fanzine" e DIY con "anarquismo". É dicir, desde o nacemento do movemento punk no 1976, a ideoloxía que o grande público lle atribiu aos fanzines foi a "anarquista" ou a do "anarquismo". Quizais pola falta dunha liña editorial e tamén polo uso, case abusivo, de simboloxía anarquista (Sabin e Triggs, 2000: 2).

\section{Imaxe 14}

Cartel feito por movementos veciñais opostos á construcción dunha estrada e o derrube de casas e eliminación de bosques. O D.I.Y. supón apartarse das consideradas canles establecidas e ser autosuficiente, mesmo para a creación editorial.

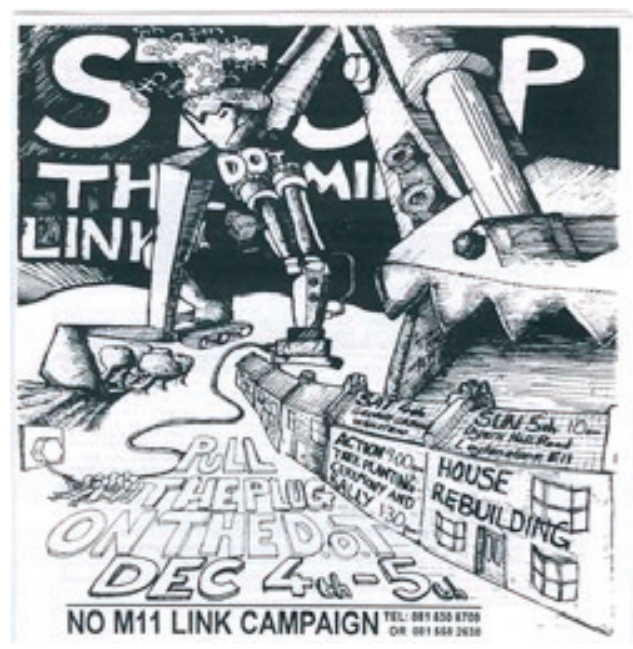

Fuente: https://www.permanentculturenow.com/introduction-to-diy-counterculture/

Concretando, o DIY dos fanzines sería un acto tanto político como cultural. Persoas con desexos de expresar as súas posturas, de maneira individual ou colectiva, recorren ao uso de materiais baratos, accesibles e a un discurso político-ideolóxico moitas veces rudimentario ou simple, para materializalo en publicacións consumidas normalmente dentro dun círculo de xente próxima a quen crea o fanzine. O obxectivo 
do DIY sería visibilizar e empoderar individuos e/ou colectivos fronte aos grandes medios, cos que non se senten nin identificados nin escoitados.

Por tanto, o DIY (faino ti mesmo) sería unha postura ideolóxica ao non querer contar con investimentos alleos, non querer ser influídos e ter unha liña editorial propia, rexeitar as regras legais para a publicación de medios impresos, total e completa independencia de influencias externas e por tanto, independencia para publicar.

A pregunta de se existe ideoloxía detrás das publicacións denominadas fanzines ten por resposta un si. Se nos cinguimos a definicións aceptadas como as de Eagleton, Thompson e Atton, podemos concluír que os fanzines son medios de expresión amateur, nacidos da necesidade de expresión por parte de determinados grupos sociais que non teñen acceso aos grandes medios para emitir as súas posturas. Ademais disto, o fanzine é un medio de comunicación que no seu proceso de elaboración crea un feito distintivo, o "faino ti mesmo" (do inglés "Do It Yourself", DIY). Este elemento permite darlle unha personalidade propia e característica ao fanzine, ao mesmo tempo que visibiliza postulados normalmente non aceptados pola maioría social ou que teñen escasa difusión.

\section{Bibliografía}

ABRIL FERNÁNDEZ, José Ángel (2011). Fanzines y otras publicaciones alternativas o marginales en Extremadura (1976-1996). Catálogo y aproximación a su lugar en el contexto sociopolítico y cultural. Trabajo Fin de Máster. Badajoz: Universidad de Extremadura, Facultad de Biblioteconomía y Documentación.

ATTON, Chris (2002). Alternative media. London: SAGE Publications Ltd.

BARTEL, Julie (2004). From A to Zine: Building a Wining Zine Collection. Chicago: American Library Association.

DOWNING, John (2010). "Nanomedios de comunicación. ¿Medios de comunicación comunitarios? ¿O de red? ¿O de movimientos sociales? ¿Qué importancia tienen?" Cátedra UNESCO de Comunicación, INCOM-UAB. Barcelona: Fundación CIDOB, (15/03/2010).http://www.portalcomunicacion. com/catunesco/download/2010_DOWNING_NANOMEDIOS\%20DE\%20 COMUNICACI\%D3N.pdf

EAGLETON, Terry (1997). Ideología. Una introducción. Barcelona: Paidós Básica.

EYERMAN, Ron e Andrew JAMISON (1991). Social Movements: a Cognitive Approach. Cambridge: Polity Press. p.106.

FERNÂNDEZ MARIÑO, Ramón (2015). O fanzine e a ruptura do monopolio da mensaxe. Uso dos fanzines como medios informativos e de expresión en Galicia. 1990-2005. Tese doutoral. Universidade de Santiago de Compostela.

FISKE, John (1989). Understanding popular culture. London: Routledge. 
GALLEGO PÉREZ, Juan Ignacio (2009). “Do It Yourself, cultura y tecnología”. Icono, Vol. 7, No 2: 13.

HEBDIGE, Dick (2013). Subcultura: El significado del estilo. Barcelona: Paidós Comunicación.

JENKINS, Henry; http://henryjenkins.org/

MCLUHAN, Marshall (2009). Comprender los medios de comunicación. Las extensiones del ser humano. Barcelona: Bolsillo Paidós, p. 31.

MOSKOWITZ, Sam e Joe SANDERS (1994). The Origins of Sicience Fiction Fandom: A Reconstruction. Westport, CT: Greenwood Press. p. 17-36.

PERKINS, Stephen (1992). "Aproaching the 80's zine scene". www.zinebook.com/ resource/perkins.html.

SABIN, Roger e Teal TRIGGS (2000). Below the critical radar. Fanzines and alternative comics from 1976 to now. Hove: Slab-o-concrete-UK. p. 2.

THOMPSON, John Benjamin (1998). Los media y la modernidad. Una teoría de los medios de comunicación. Barcelona: Paidós Comunicación. pp. 36-38.

\section{Ligazóns}

\section{CHAUVENET, L. R.}

https://es.wikipedia.org/wiki/Russ_Chauvenet

\section{DETOURS}

http://fancyclopedia.org/Detours

https://jimdoran.art/joie-de-vivre/zine-scene

\section{D.I.Y.}

https://www.permanentculturenow.com/introduction-to-diy-counterculture/ 
